\title{
Understanding Sampling and Recruitment in Social Work Dissertation Research
}

\author{
Rebecca G. Mirick \\ Ashley Davis \\ Stephanie P. Wladkowski
}

\begin{abstract}
The field of social work has increasingly focused on improving the quantity and rigor of its research. For many social work doctoral students, their first independent research experience begins with their dissertation, and yet, little is known about the factors that facilitate students' success during this process. Sample recruitment is one step where significant and unexpected challenges can occur. As social justice is the central value of the profession, social work doctoral students may focus on research with vulnerable or marginalized populations; however, little research has been done that focuses on social work dissertations, samples used, and the process of recruitment. In this study, 215 doctoral-level social work graduates who completed their degree within the past ten years were surveyed about their dissertation research, with a focus on the sampling strategy and recruitment processes. Findings show that students have a wide diversity of experiences with the dissertation process. While $64.6 \%$ anticipant challenges around recruitment and sampling, only $54.9 \%$ encounter challenges. Less than half (44.7\%) of study participants received guidance during this process and most (80.5\%) felt the dissertation experience impacted subsequent research, both positively (40.5\%) and negatively (9.8\%). Based on these findings, doctoral programs are encouraged to increase supports available to dissertating students, particularly those recruiting study participants from vulnerable and marginalized populations. These supports include community connections, skills for obtaining gatekeeper buy-in, and both relational support and advice from dissertation committees and other colleagues.
\end{abstract}

Keywords: Dissertation; social work education; recruitment; sampling; empirical research

Doctoral education prepares social work scholars to participate in the development and dissemination of professional knowledge. Doctoral students are socialized to value and contribute to the knowledge base on topics of importance to the profession that advance social justice. These emerging scholars learn the methodological and analytical skills through coursework and research practicum (Jenson, 2008), and then further develop and demonstrate this skill set through the completion of a dissertation. Sampling and recruitment are preliminary and integral steps in designing a research study, which entail defining the population of interest and soliciting eligible, willing participants (Pettus-Davis, Grady, Cuddeback, \& Scheyett, 2011). In social work research, sampling approaches are among methodological decisions that reflect the profession's values and concerns. Challenges with recruitment and retention, especially of vulnerable and marginalized populations, are common. When unanticipated, such challenges can derail and delay research.

Rebecca G. Mirick Phd, MSW is an Assistant Professor, School of Social Work, Salem State University, Salem, MA 01970. Ashley Davis, PhD, MSW is an Assistant Professor, Wheelock College, Boston, MA 02215. Stephanie P. Wladkowski, PhD, MSW, is an Assistant Professor, Eastern Michigan University School of Social Work, 900 Oakwood St., Ypsilanti, MI, 48197. 
In a review of social work dissertation research $(n=593)$, Maynard, Vaughn, and Sarteschi (2012) found that the majority of doctoral students (61\%) collected primary data, allowing them to further develop sampling and recruitment skills. While numerous textbooks offer "practical roadmaps on how to define, recruit, and retain a sample" (Abrams, 2010, p. 537), the social work literature has paid far less attention to this methodological issue, especially in terms of potential pitfalls or successful approaches. The latter is especially important as even experienced researchers face barriers in recruitment, particularly when accessing hard-to-reach or vulnerable populations (Jessiman, 2013).

Many social work doctoral students have an interest in conducting research on topics that address social inequities and support the needs of marginalized or vulnerable populations. They perceive an ethical responsibility to be inclusive and approach research from a social justice perspective (National Association of Social Work, 2008). This includes having a representative sample, striving to include those who have the greatest needs, are exposed to the greatest risk, or have experienced disparities in outcomes (Casado, Negi, \& Hong, 2012). By doing this, social work researchers conduct rigorous, relevant studies with attention to ethics, social justice, and cultural competence, creating research which reflects the values and priorities of the profession.

The present study explored recent social work doctoral graduates' experiences with sampling and recruitment in their dissertation research. The study aimed to provide a firsthand understanding of the impact of these challenges and describes the guidance and resources needed to successfully complete primary data collection for a dissertation.

\section{Literature Review}

Social work has made intentional efforts to increase its research capacity and build a unique body of knowledge as a means of establishing itself as a distinct profession (Maynard, Vaughn, Sartaschi, \& Berglund, 2014). Social work doctoral education awards two advanced degrees: Doctor of Philosophy (PhD) and Doctor in Social Work (DSW) (Diaz, 2015). The $\mathrm{PhD}$, with an emphasis on research and scholarship (Kurzman, 2015), remains the dominant doctoral degree in social work. There has been a resurgence in DSW programs for advanced practitioners (Diaz, 2015), but these programs tend to value many forms of scholarship beyond empirical research and may not require a dissertation (Anastas \& Videka, 2012).

Over the past 20 years, the Group for the Advancement of Doctoral Education in Social Work (GADE) has focused on the education of researchers (Berzoff \& Drisko, 2015). GADE describes research expertise as among the specific knowledge and skills that graduates should possess. These skills "involve the systematic collection and analysis of data that shed light on research questions relevant to social work" (GADE, 2013, p. 3). In this way, social work research has the potential to "address the problems confronting practitioners, administrators, policymakers, and the clients they serve" (Rothwell, Lach, Blumenthal, \& Akesson, 2015, p. 59). Doctoral-level social workers need to be trained in the methods that will generate and disseminate knowledge of importance to the field (Maynard et al., 2014). 
Anastas (2012) describes the dissertation as the signature pedagogy of doctoral education in social work as doctoral students learn experientially about the research process, develop research skills, and gain expertise with a body of knowledge. The dissertation requires the doctoral student to learn how to manage an individual research project. The dissertation period may last longer than the coursework phase of doctoral studies, shape future research plans, and for some, result in unfinished research and unearned doctoral degrees (Anastas \& Videka, 2012).

An additional challenge for social work research is that dissertation research is often not disseminated within the field. For a random sample of social work doctoral dissertations ( $\mathrm{n}=593)$, Maynard and colleagues (2014) found that only $28.8 \%$ were published in peer-reviewed articles or books due to the inconsistent quality of the research, a lack of attention on writing for publication in doctoral training, and insufficient supports for navigating the process. When dissertations remain unpublished, the knowledge base of the profession does not benefit from the findings. The field has a vested interest in preparing the next generation of doctoral-level social workers to be skillful researchers who can successfully complete and disseminate their findings.

\section{Research Preparation in Doctoral Education}

Doctoral programs vary in their approaches to preparing students to engage in rigorous research. In a content analysis of PhD programs (n=69), Drisko, Hunnicutt, and Berenson (2015) found that curriculum requirements varied widely but all programs required two to four research courses. Only 58\% of social work doctoral programs require a research internship (Drisko et al., 2015) and therefore, some students gain research experience only through their dissertation work. This reality highlights the importance of the dissertation as a critical opportunity to learn research skills and generate findings for the social work community, and may make it more challenging to both plan a successful research study and disseminate the results effectively.

Some doctoral students do not gain experience in the recruitment of study participants if they choose to use secondary data analyses in their dissertations. The number of social work dissertations that use secondary data analyses has increased over time (Maynard et al., 2012). Secondary data analyses tend to be inexpensive and efficient, require minimal infrastructure, foster high productivity with publications (Howard, 2009), and allow students to have access to large data sets with numerous variables and representative, random samples (Maynard et al., 2014). However, they do not offer students the opportunity to engage in the steps of the research process prior to data analysis (Lepp, Remmik, Karm, \& Leijen, 2013). The learning that arises from carrying out a primary research study is invaluable in acquiring a broad range of research skills, particularly when the reality of conducting research often is quite different than textbook descriptions (Narui, Truong, \& McMickens, 2015).

\section{Sampling, Recruitment, and Retention}

Conducting research involves many discrete skills, including conceptualizing a study, operationalizing concepts, identifying or creating instruments, collecting data, and 
analyzing the findings. Creating a sampling strategy that is congruent with the purpose and design of the study, and recruiting and retaining participants are key skills. Social work research textbooks, such as Rubin and Babbie (2013) and Thyer (2014), describe sampling and recruitment techniques in detail as a straightforward and linear process. The reality is that this process may be fraught with challenges that could negatively impact the study or researchers themselves (Narui et al., 2015). In designing a sampling strategy, addressing slow recruitment, or ensuring sufficient retention, social work researchers need to consider common, although not frankly or frequently discussed challenges, including accessing hard-to-reach populations and resolving logistical and ethical issues.

Accessing hard-to-reach populations. Social work research often involves describing the experiences of diverse populations. These studies may include samples from groups that are stigmatized or vulnerable, where there may not be a ready-made sampling frame or easy way to access the population, which makes it difficult to locate individuals. For example, research may involve a non-associative population; these individuals share a trait, such as being HIV+, but do not know each other or receive services together (Thompson \& Phillips, 2007).

A clear sampling frame, however, does not ensure participants will be easy to reach or willing to participate. Due to concerns about power imbalances and the potential for coercion, many Institutional Review Boards (IRBs) require indirect recruitment methods, having a third-party agency share study information, and requiring potential participants to contact the researchers themselves (Abrams, 2010). Indirect recruitment entails multiple levels of support needed to access a specific population, including administrative staff. At any stage of this process, gatekeepers may not support the project, derailing recruitment. Gatekeepers may lack the time and motivation to devote to research projects or may appear supportive, but perceive research as harmful or even predatory towards clients (Mirick, 2016).

The specific traits or characteristics of a vulnerable population can impact research participation. Community members themselves can be instrumental in helping researchers design and execute a study that is sensitive to the cultural norms and needs of a population. For example, Gelman (2010) described social work research with Latino caregivers of patients with Alzheimer's disease whose sense of caregiving burden was so large that participation in a supportive intervention was perceived to be onerous. The input of community members was necessary to anticipate this barrier to recruitment. Community members can provide an invaluable perspective on a study that successfully recruits hardto-reach populations.

In order for research findings to be generalized, the sample must be representative and thus diverse. One challenge to recruiting a diverse sample is that historically, some researchers have engaged in practices that deceive, violate, or otherwise harm members of oppressed groups, which has eroded the trust of some groups and increased their reticence to participate in studies (Moore \& Collins, 2002). When researchers endeavor to recruit a diverse sample, they may default to convenience sampling. This can have the unintended consequence of privileging the experiences of people who are easy to reach and willing to participate (Abrams, 2010). Researchers often settle for non-representative samples when 
achieving more diversity in the sample seems unfeasible (Descartes, Asencio, \& Blank, 2011).

Researchers have a responsibility to use culturally competent practices to recruit and retain potential participants. Effective communication with the community of interest is imperative, and may involve partnering with bilingual or bicultural individuals who can facilitate and provide interpretation (Casado et al., 2012). Social work research is a relational endeavor, particularly when engaging cross-culturally or with marginalized populations, and thus, utmost attention must be given to nurturing and sustaining relationships with community partners and participants throughout the project (Amador, Travis, McAuley, Bernard, \& McCutcheon, 2006). Such collaboration and regular contact is an investment of time and effort that cannot be shortchanged for effective recruitment and retention.

Ethical and logistical issues. Depending on the population of interest, recruitment may involve ethical issues. For example, when Descartes and colleagues (2011) aimed for a racially and socioeconomically diverse sample of gay men, they encountered challenges in preserving the integrity of their data while protecting participants. The researchers offered a monetary incentive, which led some potential low-income participants to misrepresent their demographic backgrounds to match eligibility criteria highlighting the need for clear and ethical recruitment guidelines. Sometimes social work researchers carry out studies with populations whose social and health problems reflect great needs, and yet whose participation may expose them to physical, emotional, financial, or legal harm. Kyriakakis, Waller, Kagotho, and Edmond (2014) studied the experiences of intimate partner violence and help-seeking with Mexican immigrant women, in order to inform culturally appropriate services and interventions. Due to the inherent risks for participants, the researchers needed to make accommodations to protect their physical safety, provide emotional support, and ensure anonymity. These researchers demonstrated the ethical responsibility to be adequately trained to recognize and account for the risks faced by participants, particularly from marginalized and vulnerable populations.

In addition to ethical challenges, logistical constraints may affect sampling and recruitment. Some effective strategies for locating and retaining an unbiased sample of research participants are prohibitively expensive and time-consuming, such as paying for media advertising, offering gift vouchers as inducement, investing in an immersive participatory approach, or combining mail, telephone, and face-to-face methods (Thompson \& Phillips, 2007).

Few studies offer insight into the journey towards the successful recruitment of research participants, particularly for dissertation research. The present study explored the experiences of social work doctoral graduates who carried out primary data collection for their dissertation research. Successes, challenges, supports, and lessons learned from the experience were examined as well as how students were impacted by their experiences with recruiting and retaining study participants. 


\section{Methods}

\section{Procedure}

This study used a convenience sample. Respondents needed to have earned a $\mathrm{PhD}$ in social work in the previous 10 years and recruited study participants for their dissertation research. Doctorates in Social Work (DSW) degrees were excluded, as few DSW programs require a traditional dissertation (Diaz, 2015). Participants were recruited in three ways. First, an online survey was shared through social media and social networks. Second, doctoral program directors belonging to GADE were contacted via email and asked to share the study information and survey link with alumni. Third, a search of completed social work dissertations on the ProQuest Dissertation and Theses database identified 3392 potential participants, who completed dissertations in the prior ten years and recruited study participants. The survey information and link was emailed to those for whom contact information was found $(45 \%, n=1,533)$.

\section{Data Collection}

Following IRB approval, data were collected over a three-month period from January to March 2015, using an online Qualtrics survey. The survey consisted of 40 open-and closed-ended questions about the dissertation experience, and questions on participant demographics and dissertation and program characteristics. The survey was piloted with five social work doctoral students, and was revised based on their feedback.

\section{Data Analysis}

Descriptive statistics were used to determine the mean, standard deviation, range, and/or frequencies for demographic (gender, race, age at graduation, current role), dissertation (research method, planned sample size), and program data (program type, length of time in program, and years since graduation). See Table 1.

The narrative data were uploaded to a separate Excel spreadsheet for each survey question. The researchers conducted a thematic analysis to identify themes and exemplars across the data (Braun \& Clarke, 2006; Denzin \& Lincoln, 2011). The dissertation topics were coded using the 22 topical areas established by the Society of Social Work and Research (2016) (See Table 2). For the other questions, all three researchers did a preliminary coding of $20 \%$ of the responses. This inductive process identified "units of meaning" from the data, which were combined or teased apart to refine and form a set of codes to use in coding the rest of the data. For each question, two of the researchers independently used these codes to analyze the remaining uncoded data, and the third researcher reviewed the coding decisions and reconciled any discrepancies. This step enhanced the trustworthiness and credibility of the findings by ensuring the inter-rater agreement and fidelity of coding decisions (Denzin \& Lincoln, 2011). Similar codes were reported in thematic categories, and each theme needed to represent at least $10 \%$ of the responses for the question. These themes are presented to give a clear picture of the experience of the overall sample. See Table 3. In addition, exemplars are used to illustrate 
the themes and provide more depth about respondents' experiences with sampling and recruitment in dissertation research (Braun \& Clarke, 2006).

\section{Findings}

\section{Respondents}

The sample consisted of 215 doctoral graduates who completed social work doctoral programs from 2005-2015 ( $M=5.1$ years since graduation) and recruited study participants for their dissertation research. The majority $(73.0 \%, \mathrm{n}=143)$ of respondents identified as female and white $(81.2 \%, \mathrm{n}=155)$. The mean duration of their doctoral degree program was 5.5 years. Approximately one half $(49.3 \%, n=106)$ used samples of marginalized or vulnerable populations (e.g., youth in foster care, prison inmates, refugees). See Table 1.

Table 1. Respondent Demographics, Dissertation, and Program Information

\begin{tabular}{|c|c|c|c|}
\hline & $n(\%)$ & $M(\mathrm{SD})$ & Range \\
\hline \multicolumn{4}{|l|}{ Gender $(\mathrm{n}=196)$} \\
\hline Female & 143 (73\%) & & \\
\hline Male & $48(24.5 \%)$ & & \\
\hline Transgender & $5(2.6 \%)$ & & \\
\hline \multicolumn{4}{|l|}{ Race ( $\mathrm{n}=191)$} \\
\hline White & 155 (81.2\%) & & \\
\hline Black & $13(6.8 \%)$ & & \\
\hline Asian & $12(6.3 \%)$ & & \\
\hline Biracial & $5(2.6 \%)$ & & \\
\hline Latino & $4(2.1 \%)$ & & \\
\hline Native American & $2(0.5 \%)$ & & \\
\hline \multicolumn{4}{|l|}{ Type of program (n=196) } \\
\hline Full-time & 149 (75.3\%) & & \\
\hline Part-time & $49(24.8 \%)$ & & \\
\hline Years in program $(\mathrm{n}=195)$ & & $5.5(2.4)$ & \\
\hline Age at graduation $(\mathrm{n}=193)$ & & $41.5(8.9)$ & $29-71$ \\
\hline Years since graduation $(n=196)$ & & $5.1(3)$ & $1-10$ \\
\hline \multicolumn{4}{|l|}{ Research Method $(n=215)$} \\
\hline Qualitative & $96(44.7 \%)$ & & \\
\hline Quantitative & $49(22.8 \%)$ & & \\
\hline Mixed Methods & $70(32.6 \%)$ & & \\
\hline Planned Sample Size (n=198) & & $171.7(338.3)$ & $5-3000$ \\
\hline Vulnerable Sample & 106 (49.3\%) & & \\
\hline \multicolumn{4}{|l|}{ Current Role $(\mathrm{n}=191)^{\mathrm{a}}$} \\
\hline Faculty & $145(67.4 \%)$ & & \\
\hline Practitioner & $40(18.6 \%)$ & & \\
\hline No paid employment & $16(7.4 \%)$ & & \\
\hline Other employment & $26(12 \%)$ & & \\
\hline
\end{tabular}


Dissertation topics were categorized as mental health (17.2\%, $n=37)$, health $(9.3 \%, n=20)$, aging services and gerontology $(8.8 \%, \mathrm{n}=19)$, child welfare $(8.8 \%, \mathrm{n}=19)$, and violence against women and children $(7.9 \%, \mathrm{n}=17)$. See Table 2 for the list of all 22 topics.

Table 2. Dissertation Topics Based on SSWR Codes $(n=215)$

\begin{tabular}{lc}
\hline Topic & n (\%) \\
\hline Mental Health & $37(17.2 \%)$ \\
Health & $20(9.3 \%)$ \\
Aging Services \& Gerontology & $19(8.8 \%)$ \\
Child Welfare & $19(8.8 \%)$ \\
Violence against Women \& Children & $17(7.9 \%)$ \\
Social Work Practice & $14(6.5 \%)$ \\
Race, Ethnicity, \& Immigration & $13(6 \%)$ \\
Work, Family, \& Family Policy & $13(6 \%)$ \\
Inequality, Poverty, \& Social Welfare & $12(5.6 \%)$ \\
Crime \& Criminal Justice & $10(4.7 \%)$ \\
Social Work Education & $9(4.2 \%)$ \\
Gender & $8(3.7 \%)$ \\
Substance Misuse \& Addictive Behaviors & $8(3.7 \%)$ \\
Adolescent \& Youth Development & $7(3.3 \%)$ \\
Sexual Orientation \& Gender Identity & $7(3.3 \%)$ \\
Organizations \& Management & $7(3.3 \%)$ \\
Communities \& Neighborhoods & $6(2.8 \%)$ \\
School Social Work & $5(2.3 \%)$ \\
Disability & $4(1.9 \%)$ \\
International Social Work \& Global Issues & $4(1.9 \%)$ \\
Military Service Members, Veterans, \& their Families & $4(1.9 \%)$ \\
Research Design \& Measurement & $0(0 \%)$ \\
\hline Note: There are 243 responses because 28 dissertation topics fell \\
equally into two categories.
\end{tabular}

Respondents provided detailed examples of their experiences with the recruitment of study participants for their dissertation. Topics of inquiry included anticipated challenges, observed challenges, perceived strategies that led to success, supports, and the impact of the experience on their identity as a scholar and future research. See Tables 3a-d.

\section{Anticipated Challenges Prior to Recruitment}

Nearly two-thirds of respondents $(64.7 \%, \mathrm{n}=139)$ expected the recruitment process to present challenges, even before they engaged in the research. Those reporting (63.7\%, $n=$ 137) described anticipated challenges in three primary categories: 1) access to eligible participants $(49.6 \%, n=69), 2)$ research design to gather an adequate sample size (46.5\%, $\mathrm{n}=66$ ), and 3) commitment from gatekeepers and potential participants 395.4\%, $n=54$ ). 
Table 3a. Survey Questions, Number of Respondents, and Themes: Anticipated Challenges Prior to Recruitment $(n=215)$

\begin{tabular}{|lr|}
\hline Question & $\mathbf{n}(\mathbf{\%})$ \\
\hline \multicolumn{2}{|l|}{ Prior to beginning recruitment, did you anticipate any challenges? (n=215) } \\
$\quad$ Yes & $139(64.7 \%)$ \\
If yes, what were they? (n=137)* & \\
Access to sample & $69(49.6 \%)$ \\
Research design & $66(47.5 \%)$ \\
Logistics & $30(45.5 \%)$ \\
Sample size & $36(54.6 \%)$ \\
Buy-in & $54(39.4 \%)$ \\
Gatekeepers & $25(46.3 \%)$ \\
Participants & $29(53.7 \%)$ \\
If not, why not? (n=76)* & \\
Access to sample & $38(50.0 \%)$ \\
Research design & $25(32.9 \%)$ \\
Incorrect assumptions & $17(22.4 \%)$ \\
\hline${ }^{a}$ note: participants chose more than one answer \\
\hline
\end{tabular}

Access to eligible participants. Nearly one-half $(49.3 \%, \mathrm{n}=106)$ of respondents recruited from vulnerable or marginalized populations. However, less than one-third (32.1\%) expected challenges gaining access to participants from hard-to-reach (50.7\%, $n=35)$ or stigmatized groups $(49.3 \%, n=34)$. One respondent described her awareness of the difficulty connecting with vulnerable individuals, saying, "I knew that trying to recruit...trafficking victims would be difficult due to the underground nature of this population in addition to [the] stigma that this group experiences.” Another respondent said, "I anticipated challenges in recruiting immigrant women, due to the potential concerns regarding their safety and anonymity." One respondent described, "HIV is a sensitive issue...." Participants identified realistic challenges to accessing study participants.

Research design. For $47.5 \%$ ( $n=66$ ) of respondents, recruitment concerns focused on issues related to the research design. For 54.6\% $(n=36)$, obtaining the ideal sample size felt unrealistic. One respondent described, "Fifty [participants] was a large sample and I was concerned about how long it would take to achieve this sample size." Another listed anticipated barriers, "It would be hard to find participants, no one would volunteer, or volunteers would not be competent or able to provide thick description." Thirty respondents (45.5\%) were concerned about the necessary logistics for participation within the study's design. One said, "Prospective participants were physically ill and some would potentially be unable to participate due to severity of illness or the intensity of the services received," highlighting how the particular vulnerabilities of the sample can create logistical barriers to data collection.

Commitment from others. Approximately three-quarters $(74.9 \%, n=161)$ of the respondents did not anticipate challenges getting buy-in from gatekeepers or participants. The $25.1 \%(n=54)$ who did foresee these challenges thought they would focus specifically 
around obtaining buy-in from potential gatekeepers $(46.3 \%, \mathrm{n}=25)$ or participants $(53.7 \%$, $\mathrm{n}=29$ ). Concerns about gatekeeper buy-in were varied, including time, willingness, sensitive topics, and research design requirements. For example, one respondent said, "It was challenging to find agencies that would agree to allow me to recruit their service providers due to concerns about over-burdening staff with participation.” Another said, "I recognized that there may be resistance to the research design and that there would be layers of administrative and caregiver support required before access to residents would be possible." One respondent described the anticipated challenges of indirect recruitment strategies saying, "I expected that it might be difficult to get enough participants because IRB procedures did not allow me to contact them directly but rather to go through [Child Protective Services]", while another said, "I was also relying on service providers to do the recruitment, which left the recruitment out of my control."

Challenges to participant buy-in included time, the topic of the study, and the researcher's lack of membership in the community. One respondent said, "I was concerned that potential respondents would simply not have the time or interest to participate." Another said "finding couples who would be willing to participate... and would agree to be video-taped,” or “...these busy professionals would not be willing/able to give me the time." One participant described, "The subject matter is 'heavy'. I anticipated that....people would not be ready to talk about their experiences with homicide," while another said, "adolescents not wanting to speak to a stranger and open up about their experiences with parents with terminal cancer." Two respondents described the impact of not belonging to the community, saying, "Being an outsider was also seen as a limitation to gaining a commitment" and, "This was cross-cultural work that was related to a very sensitive topic/population. I anticipated resistance or guardedness from interview participants in speaking to a foreigner.”

Almost one-quarter $(22.4 \%, \mathrm{n}=17)$ of the respondents who did not anticipate challenges (35.3\%, $n=76)$ attributed this to incorrect assumptions about the feasibility of the research plan. For example, "I figured snowball sampling would be relatively straightforward. It was not.” This represents only a small percentage $(7.9 \%, \mathrm{n}=17)$ of the total sample.

\section{Observed Challenges During Recruitment}

Over half of respondents $(54.9 \%, \mathrm{n}=118)$ experienced recruitment challenges during their dissertation. These challenges can be categorized as access to eligible participants $(28.7 \%, n=35)$, response rate $(18.1 \%, n=39)$, and logistics for participation $(10.2 \%, n=22)$.

Accessibility. Just over one-quarter $(28.7 \%, \mathrm{n}=35)$ of respondents reported issues with obtaining access to eligible participants. One respondent described, "I was not allowed to use the listserv myself, instead relying on an administrator at the university to do so." Another said, "My committee insisted that I canvas agencies in the [city name] and since those places were not known to me, I did not get any volunteers.” 
Table 3b. Survey Questions, Number of Respondents, and Themes: Observed Challenges During Recruitment $(n=215)$

\begin{tabular}{|lc|}
\hline Question & $\mathbf{n ( \% )}$ \\
\hline Did you encounter any challenges with recruitment? (n=215) & \\
Yes & $118(54.9 \%)$ \\
If yes, describe the challenges you encountered. (n=122) & \\
$\quad$ Access to sample & $35(28.7 \%)$ \\
Gatekeeper buy-in & $22(18.0 \%)$ \\
Response rate & $39(32.0 \%)$ \\
Logistics & $22(18.0 \%)$ \\
If not, what factors do you think contributed to this success? (n=89) \\
Data collection methods & $51(57.3 \%)$ \\
$\quad$ Gatekeeper support & $26(51.0 \%)$ \\
$\quad$ Logistics & $15(29.4 \%)$ \\
$\quad$ Participant contact & $10(19.6 \%)$ \\
Participant buy-in & $30(33.7 \%)$ \\
\hline Did these challenges impact your recruitment strategy? (n=114) \\
Yes & $62(54.4 \%)$ \\
If yes, how?* & $25(40.3 \%)$ \\
Revised recruitment & $17(27.4 \%)$ \\
Decreased sample & $16(25.8 \%)$ \\
Changed criteria & $26(41.9 \%)$ \\
More effort & $25(45.6 \%)$ \\
\hline Did these challenges delay completion of your dissertation? (n=55) \\
Yes \\
\hline anote: participants chose more than one answer \\
\hline \multicolumn{2}{|l}{} \\
\hline
\end{tabular}

Gatekeeper buy-in. Only $18.0 \%(n=22)$ identified challenges obtaining gatekeeper buy-in. One respondent described a lack of connections, saying, "It was just timeconsuming trying to find enough fathers to include...I had also become somewhat isolated during my PhD work and had fewer people I could contact.” For those using indirect recruitment, challenges to obtaining gatekeeper buy-in could be multilayered, such as, "Having the support of the administrators...did not always translate to nursing staff or social service provider engagement. As a result, it was possible for the study to be derailed at any step in the process." One respondent described gatekeepers as "suspicious and protective of their clients." Another said, "Not all directors were willing to send out my link for fear of overwhelming staff more."

Response rate. Less than one-fifth $(32.0 \%, n=39)$ of respondents identified challenges obtaining participant buy-in, resulting in a low response rate. One described bluntly, "Response rate sucked (only 136 completed surveys within two months). Participants agreed to participate and then didn't return surveys.” One respondent described a continual struggle, "lack of response to initial letters, lack of response to follow-up emails and phone calls." Various issues were blamed for low response rates. One attributed the challenges to 
"Incorrect information to mail out the recruitment letters---addresses were wrong, people had moved, phone numbers were incorrect." Another described the intersection of gatekeeper and participate buy-in challenges, saying, "Participants cancelled or did not show, difficult to obtain buy-in from some directors...."

Logistics. Only $18.0 \%(n=22)$ of respondents reported logistical barriers, such as obtaining consent for participation and transportation to research sites. One respondent said, "It was very difficult to get participants to travel to the face-to-face interviews...most cited difficulty arranging child care and transportation, or scheduling difficulties that conflicted with work." Another respondent said, "Transportation to the VA was also triggering for some dealing with PTSD. They wanted to participate over the phone, but IRB requirements wouldn't allow it.”

Responses to challenges. Respondents addressed these challenges by putting in more effort, including accessing community connections $(22.0 \%, \mathrm{n}=26)$, revising recruitment plans $(214.2 \%, n=25)$, decreasing the sample size $(14.4 \%, n=17)$, and changing the eligibility criteria for participation $(13.6 \%, n=16)$. For $21.2 \%(n=25)$ of respondents, recruitment challenges delayed the completion of the dissertation. The mean delay time was 3.4 months $(\mathrm{SD}=0.50)$.

\section{Perceived Strategies of Success}

The primary reasons for anticipated success were access to or prior experience with the sample $(50.0 \%, n=38)$ and the perceived feasibility of the research design $(32.9 \%$, $\mathrm{n}=25)$. The 89 respondents $(41.4 \%)$ who experienced successful recruitment attributed their success to factors which fell into two major categories: 1) data collection methods $(57.3 \%, \mathrm{n}=51)$ and 2$)$ participant buy-in $(33.7 \%, \mathrm{n}=30)$.

Data collection methods. The methods seen as contributing to success included working with professionals and gatekeepers who supported the project, sometimes due to the researcher's connections or relationships with them $(51.0 \%, n=26)$, simple enrollment logistics 29.4\%, $(n=15)$, and personal contact with participants $(19.6 \%, n=10)$. Examples included, "Actually going to the groups and meeting the women made the difference-a flyer would not have worked," using "one point person at each program," or having the participating agency facilitate participation, “...Time blocked out during their work day to participate." These strategies were viewed as increasing both the opportunities for enrollment and the ease of participation.

Participant buy-in. One-third $(33.7 \%)$ of respondents $(n=30)$ found that having participant buy-in was key to success. One respondent described this being easier than expected, saying, "People wanted to talk to us. They [were] 'honored' in a way that we were there to learn from them and wanted to hear their story...this was unexpected." Connections to the community such as a "positive professional reputation" and the researcher's membership in the community were also seen as facilitating participant buyin. One attributed her success to, "Being of Southeast Asian descent... and my relationship and status within the Southeast Asian community.” 


\section{Identified Supports Before and During Recruitment}

Respondents described the guidance they obtained prior to $(90.7 \%, \mathrm{n}=195)$ and during the recruitment process $(84.2 \%, \mathrm{n}=181)$. Almost one-third of respondents $(29.3 \%, \mathrm{n}=63)$ identified specific supports they wished were available to them during data collection.

Table 3c. Survey Questions, Number of Respondents, and Themes: Identified Supports Before and During Recruitment $(n=215)$

\begin{tabular}{|c|c|}
\hline Question & $\mathbf{n}(\%)$ \\
\hline \multicolumn{2}{|c|}{$\begin{array}{l}\text { What guidance or advice about recruitment did you receive before you } \\
\text { carried out your study? }(n=195)\end{array}$} \\
\hline Data collection & $58(29.7 \%)$ \\
\hline Recruitment & $17(8.7 \%)$ \\
\hline \multicolumn{2}{|c|}{ If you received guidance, who gave it to you? $(n=191)$} \\
\hline Chair \& committee & $93(48.7 \%)$ \\
\hline Researcher, mentor, advisor & $78(40.8 \%)$ \\
\hline Other & $19(10.0 \%)$ \\
\hline \multicolumn{2}{|c|}{$\begin{array}{l}\text { During the recruitment process, what guidance or advice did you receive } \\
\text { about recruitment? }(n=181)\end{array}$} \\
\hline Research design changes & $29(16.0 \%)$ \\
\hline None & $67(37.0 \%)$ \\
\hline \multicolumn{2}{|c|}{ If you received guidance, who gave it to you? $(n=96)$} \\
\hline Chair, committee, mentor, advisor & $51(53.1 \%)$ \\
\hline Participant \& gatekeeper & $23(24.0 \%)$ \\
\hline Other researcher & $22(22.9 \%)$ \\
\hline \multicolumn{2}{|c|}{$\begin{array}{l}\text { Are there supports you wish had been available to help you recruit } \\
\text { participants? }(\mathrm{n}=63)^{*}\end{array}$} \\
\hline Guidance & $39(61.9 \%)$ \\
\hline Methods & $18(46.2 \%)$ \\
\hline Committee & $15(38.5 \%)$ \\
\hline Resources & $35(55.6 \%)$ \\
\hline Connections & $23(65.7 \%)$ \\
\hline Financial & $12(34.3 \%)$ \\
\hline
\end{tabular}

Guidance received before recruitment. The most common sources of support were dissertation chairs and committee members $(n=93,48.7 \%)$ and senior researchers, mentors, and supervisors ( $\mathrm{n}=78,40.8 \%)$. Twenty respondents $(10.3 \%)$ reported they had very little or no guidance. Nineteen (10.0\%) cited other mentors and non-relational sources, such as classes, the IRB, and books.

Less than one-third of respondents $(29.7 \%, n=58)$ described receiving specific types of guidance related to data collection prior to the start of recruitment. Some of this advice was a reminder of the realities of research, for example, being realistic about the time required for data collection, "I was told that recruitment always takes longer than you 
expect, but even with that, I expected data collection to take 3-4 months, not a full year.” Surprisingly, only $8.7 \%(\mathrm{n}=17)$ described getting support specific to recruitment efforts, for example "how to recruit participants from different cultural backgrounds with confidentiality concerns."

Guidance received during recruitment. Almost half (44.6\%) described specific sources of guidance $(n=96)$ during recruitment of participants. Of these, 53.1\% $(n=51)$ identified dissertation chairs, committee members, mentors, and advisors. Other sources of support included study participants and gatekeepers $(24.0 \%, \mathrm{n}=23)$ and other researchers, such as outside academics and doctoral peers $(22.9 \%, \mathrm{n}=22)$. For example, one said, "I consulted with Chinese American faculty members in my university as well as asked Chinese American people." Another shared, "I talked to a friend (who was getting her $\mathrm{PhD}$ in a different university) about the problem I was having with not getting enough Black people or males in my study, and she suggested marketing directly to websites that cater to those populations." Only $16.0 \%$ of respondents $(n=29)$ described getting advice around changing the research design, such as by altering recruitment plans. One of these respondents described getting guidance from a member of the sampling frame, "She told me that mailing is not going to be effective with clergy because they get so many surveys. She suggested that I should rely more on calling them directly." Another described the advice she got from her chair as "the most helpful advice I had throughout the process." The respondent added, "she made suggestions about contacting schools and about contacting the independent living center in my area."

Sixty-seven respondents (37.0\%) reported receiving no guidance during this period. Twelve (17.9\%) did not view this as a problem, saying, "The help was available; I simply didn't ask" or "I knew my site of data collection better than my advisors." One participant noted that guidance was not always helpful, "I did not get any advice other than my committee telling me they did not think I would be able to find recruits. That was not helpful."

Desired supports. Almost one-third of respondents (29.3\%, $n=63)$ identified supports they wished had been available to them. These included more guidance $(61.9 \%, \mathrm{n}=39)$ and resources $(55.6 \%, n=35)$. In terms of guidance, $46.2 \%$ of respondents $(n=18)$ wanted methodological help, such as "more qualitative research recruiting guidance", "advice on hard-to-reach populations," and "suggest NOT sampling children in child welfare." And $38.5 \%(n=15)$ wanted more support from committees such as "more direct involvement" and "direct, helpful feedback." In terms of additional resources, 65.7\% (n=23) wanted stronger university relationships with gatekeepers or community groups. For example, one respondent shared "I wish there had been a stronger connection between the school and long-term care facilities.” Twelve respondents (34.3\%) wished for financial support, primarily for participant incentives. One said, "I paid for incentives out of my own personal funds; small university grants would have been helpful.” It is unknown how many respondents already had access to financial support for their research. 


\section{Impact of Dissertation Experience}

Impact on students. The majority of respondents $(71.6 \%, \mathrm{n}=154)$ described ways in which the dissertation experience had impacted them. More than half $(56.5 \%, n=87)$ identified positive feelings, including feeling "confident," having "enthusiasm" for research, and describing a "very positive learning experience." One described her dissertation process by saying, "I can't begin to describe what a rich experience this was. If I had to say one thing about it, it gave me a much greater understanding of my current patients." Some $(24.0 \%, \mathrm{n}=37)$ described how the experience impacted their identity as a researcher. Only $13.6 \%(n=21)$ reported negative feelings, such as, "The dissertation process was long and dreadful. I am literally burnt out from conducting my own research,” and, "It left me emotionally drained and somewhat defeated." While many more felt inspired and gained confidence from the experience, the few with negative experiences described powerful feelings, which seem to have had a lasting impression.

Table 3d. Survey Questions, Number of Respondents, and Themes: Impact of Dissertation Experience $(n=215)$

\begin{tabular}{|c|c|}
\hline Question & $\mathbf{n}(\%)$ \\
\hline \multicolumn{2}{|c|}{$\begin{array}{l}\text { Do you think your dissertation experience had an impact on your } \\
\text { subsequent research since graduating from your doctoral program? } \\
\text { (n=196) }\end{array}$} \\
\hline Yes & $173(88.3 \%)$ \\
\hline \multicolumn{2}{|c|}{ Explain in more detail how it affected you? $(n=154) *$} \\
\hline Positive feelings & $87(56.5 \%)$ \\
\hline Negative feelings & $21(13.6 \%)$ \\
\hline Future research & $56(36.4 \%)$ \\
\hline Researcher identity & $37(24.0 \%)$ \\
\hline \multicolumn{2}{|l|}{ Did it impact your... (n=175)* } \\
\hline ...willingness to engage in research? Yes & $172(98.3 \%)$ \\
\hline ...ability to engage in research? Yes & $171(97.7 \%)$ \\
\hline ...enthusiasm to engage in research? Yes & $170(97.1 \%)$ \\
\hline \multicolumn{2}{|c|}{ Have you carried out research since your dissertation? $(n=193)$} \\
\hline Yes & $134(69.4 \%)$ \\
\hline \multicolumn{2}{|l|}{ If no, why not? (n=61) } \\
\hline Other commitments & $42(68.9 \%)$ \\
\hline Recent graduate & $13(21.3 \%)$ \\
\hline Other & $16(26.2 \%)$ \\
\hline
\end{tabular}

Impact on research. The majority of the respondents $(80.5 \%, \mathrm{n}=173)$ reported that the dissertation experience impacted their subsequent research agendas. Most (97.7\%, $\mathrm{n}=171$ ) reported it influenced, either positively or negatively, their ability to engage in research, $97.1 \%(n=170)$ that it affected their enthusiasm to engage in research, and 98.3\% $(n=172)$ that it impacted their willingness to engage in research. Fifty-six $(26.1 \%)$ said that their experience influenced future research projects. One respondent said, "Child 
trafficking is very difficult to research and therefore I have moved my research focus to a more accessible population despite the need for research in trafficking." Another moved away from data collection altogether, saying, "Secondary data analysis is much easier in terms of getting publications out and I have done a lot of that since graduating." These examples illustrate ways in which respondents adapted future research plans based on their dissertation experience. More than half of the respondents ( $n=134,69.4 \%)$ reported carrying out post-dissertation research. For those who did not, the most common reasons were other commitments $(68.9 \%, n=42)$, such as teaching courses and other projects or they were recent graduates $(21.3 \%, n=13)$ who had not yet had the opportunity to engage in research post-graduation.

\section{Limitations}

Limitations to this study include the use of a non- random sample. It was challenging to determine how many social work doctoral graduates fit the eligibility criteriacompleted primary research, including recruitment-out of all possible graduates. Therefore, a response rate was impossible to accurately calculate. Some participants did not complete questionnaires, which led to lower response rates on later questions (see Table 3). This may have introduced some bias on later questions if those respondents were different in some way. Contact information for people with academic positions in the United States was the easiest to obtain, so those in faculty positions may be overrepresented. Social work doctoral students who did not graduate were not included; those students, especially those who dropped out during the dissertation process, and their experiences are therefore excluded from these findings. Future research could explore these students' experiences or focus more in-depth on challenges and successes through longer, open-ended interviews. In addition, future research could investigate more specific questions which arose from these findings, such as the rate of funding for doctoral dissertations, specific challenges and successes experienced by those engaging in longitudinal research, or possible differences in experience for qualitative versus quantitative researchers.

\section{Discussion}

This study explored the experience of planning and engaging in the recruitment process of social work dissertation research. This study solely explored the experiences of students who were eventually successful at completing their doctoral programs, although many (55.8\%) did encounter some challenges during the process. This provides a strengths-based perspective as these students found ways to be resourceful and resilient in the face of challenges. While most participants (88.4\%) were able to finish their dissertations without any delay, many participants described how they encountered recruitment challenges. Almost half (49.3\%) recruited from vulnerable populations. When working with diverse populations, recruitment challenges are an expected component of the research project. The skills involved in recruiting hard-to-reach populations, especially those who share a characteristic and yet are unrelated to one another are complicated (Abrams, 2010; Thompson \& Phillips, 2007). Students for whom the dissertation is their only researchbased experiential learning experience may need more direct guidance and advice from the 
committee; in particular, a lack of knowledge of the population or methodology may impact their overall learning. For students with research experience, this kind of support from committee members may be less necessary.

Most (81.9\%) respondents were content with their committee's support. This suggested that while only $29.7 \%$ of respondents reported having received guidance on data collection, and only $7.2 \%$ reported guidance specific to recruitment, many may not have felt the need for guidance during this process. Only a few (18.1\%) respondents reported that they wished for more guidance and support from their committee, such as practical assistance or encouragement during the sampling and recruitment stage. The committee seemed to play different roles for students; for some, they were hands-on mentors who would strategize and offer advice, but for others, committee members maintained more of an observer role. This may reflect the diversity in level of student preparation and need, as previous studies have highlighted that social work doctoral programs offer uneven (Drisko et al., 2015) or inadequate preparation in research methods (Rothwell et al., 2015).

Only $16.3 \%$ of respondents pinpointed other supports, beyond additional guidance, that would have helped them achieve success. While it is possible that for many no additional resources were needed, it could also be that respondents assumed that challenges did not stem from structural factors or from methodological issues, but from their own individual deficits, such as a lack of preparation, understanding of recruitment strategies, or skill in networking with gatekeepers. Internalizing challenges are more likely to occur in environments in which research problems are addressed quietly and not commonly discussed publicly (Curtis, Roberts, Copperman, Downie, \& Liabo, 2004). New researchers may assume others do not have these experiences, remain silent in their own struggles, and internalize their challenges.

Dissertation experiences can evoke a range of feelings as dissertations likely fulfill different needs for each student. For some, the dissertation may be an experiential learning exercise. For others, the dissertation is an opportunity to develop and demonstrate mastery of knowledge and skills needed for success with research endeavors post-graduation, such as launching a scholarly agenda for an academic career (Maynard et al., 2014). Some respondents (40.5\%) reported they left the dissertation process with positive feelings, such as confidence and pride, and an appreciation of the research process, whereas many fewer (9.8\%) left with negative feelings, such as demoralization and inadequacy. While the majority do not identify strong negative feelings, even $10 \%$ is concerning, considering that $80.5 \%$ of respondents said their dissertation experience impacted their future research. As the majority of social work doctoral students pursue careers in academia (Anastas, 2012), negative experiences may impede the initiation of a scholarly agenda or steer graduates into research projects that avoid recruitment, such as secondary data analyses, or which recruit from more easily accessible populations.

In order to help all doctoral students have a positive, successful dissertation experience, it is critical to understand the sources of success in this process. The respondents who did not face recruitment challenges (45.1\%) attributed their smooth recruitment processes to data collection strategies (57.3\%), and participants' engagement in the process (33.7\%), buy-in from gatekeepers and other professionals (29.2\%) and from participants (33.7\%), 
straightforward logistics (16.9\%), and personal contact with potential participants (11.2\%). Effective recruitment is a relational process and respondents who recognized this and engaged actively in this process seemed to meet with success. Participant and gatekeeper buy-in were recognized as important components of the process and could either facilitate or hinder recruitment as both groups need to value the research topic and recognize the importance of the findings (Axford, Lehtonen, Kaoukji, Tobin, \& Berry, 2012). The researcher's connections within the community were vital to successful recruitment, and for $10.7 \%$, even functioned as additional sources of guidance before and during the process (Casado et al., 2012; Gelman, 2010).

\section{Implications for Social Work Doctoral Education}

Over and above other sources of support, the chair and committee members play a critical role in offering guidance and support during the dissertation process. The respondents in this study cited committee members as the most common source of guidance both during the planning process (48.7\%) and while recruitment was ongoing (53.1\%). The role of the committee may be particularly critical in programs without a strong emphasis on research preparation. Social work doctoral programs pair students and their mentors in a myriad of ways that may or may not match students' populations of interest or intended research methods with faculty members' strengths, interests, and experience. Committee members may struggle to guide students when they themselves are not experts in the content area. Doctoral programs vary in how much they support faculty members during this process. At many universities, faculty members are given few incentives to prioritize mentoring or to develop their effectiveness as mentors (Liechty, Liao, \& Schull, 2009). Such institutional expectations are imperative in ensuring that committee members are willing and able to devote significant time and energy to teaching students about research through the dissertation process, particularly in programs without strong methodological preparation of its students. Social work programs can encourage and formalize other forms of mentoring, such as bringing in outside research experts and organizing peer consultation groups.

In this study, over half of respondents (54.9\%) acknowledged encountering sampling and recruitment problems although only a small percentage of these students (21.2\%) experienced a longer than anticipated recruitment process or negative feelings about the process (8.5\%). Clearly, the majority of students who encounter challenges go on to experience successful, timely recruitment and positive feelings about the process. For some though, this may be a vulnerable time period in which they need guidance and support around recruitment challenges. These challenges, however, are often not openly discussed in the professional discourse; they tend to be "airbrushed" out of methods sections, "as a result of pressure on length of journal articles, professional pride, or a disinclination for well-trained, careful researchers to admit difficulties” (Curtis et al., 2004, p. 168). Such omissions do a disservice to social work researchers who turn to the literature for strategies, guidance, and reassurance as some of the participants in this study described. Social workers have a long tradition of offering "practice wisdom" from one professional to another and doctoral-level social workers can offer "research wisdom" when they openly discuss their successes and challenges in the dissertation process, and share problem- 
solving strategies. This study is an example of this kind of sharing of "research wisdom" that can inform both current doctoral students and the programs that train them.

Finally, the challenges with sampling and recruitment have social justice implications. First, with the minimal availability of dissertation funding (Jenson, 2008), 11.3\% of respondents reported needing financial support for their project, after having to pay out-ofpocket for research expenses or forgo costly approaches or monetary incentives that would have facilitated recruitment. Unfortunately, this reality may drive some research decisions toward the priorities of funding sources or may create an undue financial burden on some students. Secondly, some respondents linked anticipated success (17.7\%) or actual success (12.1\%) with relationships, connections, and experience with community leaders, agency gatekeepers, professional experts, or participants themselves. Not all social work doctoral students or committee members have such connections to rely upon. Thus, those students with economic means or social capital may have an easier time with the dissertation process, which may in turn affect their scholarship and identity as a researcher (Ortega \& BuschArmendariz, 2014). Doctoral programs might address these inequities by matching students who need them with committee members or additional mentors with more community connections, or supporting more programmatic community connections and collaborations. Finally, $49.3 \%$ of respondents carried out research with vulnerable populations whose day-to-day realities and potential risks in participation must be considered (Kyriakakis et al., 2014). It is vital to the knowledge base of the profession to hear the voices of vulnerable populations, include their perspectives, and understand their needs. Therefore, doctoral programs need to be able to devise strategies, locate guidance, and create supports to effectively address sampling and recruitment challenges with these populations.

\section{Conclusion}

This research study describes the often invisible area of the recruitment process of dissertation research through the experiences of 215 social work PhDs. The majority identified the impact this process has on their future research. Respondents highlighted the important role of the committee as well as students' community connections. Future committee members and doctoral programs can use these experiences to support doctoral candidates in designing studies that successfully anticipate and address recruitment challenges for social work researchers.

\section{References}

Abrams, L. S. (2010). Sampling 'hard to reach' populations in qualitative research: The case of incarcerated youth. Qualitative Social Work, 9(4), 536-550. doi: https://doi.org/10.1177/1473325010367821

Amador, T., Travis, S., McAuley, W., Bernard, M., \& McCutcheon, M. (2006). Recruitment and retention of ethnically diverse long-term family caregivers for research, Journal of Gerontological Social Work, 47(3-4), 139-152. doi: https://doi.org/10.1300/J083v47n03 09 
Anastas, J. W. (2012). Doctoral education in social work. New York: Oxford University Press. doi: https://doi.org/10.1093/acprof:oso/9780195378061.001.0001

Anastas, J., \& Videka, L. (2012). Does social work need a “practice doctorate”? Clinical Social Work Journal, 40(2), 268-276. doi: https://doi.org/10.1007/s10615-012-0392$\underline{3}$

Axford, N., Lehtonen, M., Kaoukji, D., Tobin, K., \& Berry, V. (2012). Engaging parents in parenting programs: Lessons from research and practice. Children and Youth Services Review, 34(10), 2061-2071. doi: https://doi.org/10.1016/j.childyouth.2012.06.011

Berzoff, J., \& Drisko, J. (2015). What clinical social workers need to know: Bio-psychosocial knowledge and skills for the twenty-first century. Clinical Social Work Journal, 43(3), 263-273. doi: https://doi.org/10.1007/s10615-015-0544-3

Braun, V., \& Clarke, V. (2006). Using thematic analysis in psychology. Qualitative Research in Psychology, 3(2), 77-101. doi: https://doi.org/10.1191/1478088706qp063oa

Casado, B. L., Negi, N. J., \& Hong, M. (2012). Culturally competent social work research: Methodological considerations for research with language minorities. Social Work, 57(1), 1-10. doi: https://doi.org/10.1093/sw/swr002

Curtis, K., Roberts, H., Copperman, J., Downie, A., \& Liabo, K. (2004). 'How come I don't get asked no questions?' Researching 'hard to reach' children and teenagers. Child \& Family Social Work, 9(2), 167-175. doi: https://doi.org/10.1111/j.13652206.2004.00304.X

Denzin, N. K., \& Lincoln, Y. S. (2011). The SAGE handbook of qualitative research. Thousand Oaks, CA: Sage.

Descartes, L., Asencio, M., \& Blank, T. O. (2011). Paying project participants: Dilemmas in research with poor, marginalized populations. Advances in Social Work, 12(2), 218-225.

Diaz, M. (2015). The "new” DSW is here: Supporting degree completion and student success. Journal of Teaching in Social Work, 35(1-2), 101-115. doi: https://doi.org/10.1080/08841233.2014.972013

Drisko, J., Hunnicutt, C., \& Berenson, L. (2015). A national content analysis of PhD program objectives, structures, and curricula: Do programs address the full range of social work's needs? Journal of Teaching in Social Work, 35(1-2), 14-28. doi: https://doi.org/10.1080/08841233.2014.986356

Gelman, C. R. (2010). Learning from recruitment challenges: Barriers to diagnosis, treatment, and research participation for Latinos with symptoms of Alzheimer's disease. Journal of Gerontological Social Work, 53(1), 94-113. doi: https://doi.org/10.1080/01634370903361847

Group for the Advancement of Doctoral Education in Social Work. (2013). Quality 
guidelines for PhD programs in social work. Retrieved from http://www.gadephd.org/Portals/0/docs/GADE\%20quality\%20guidelines\%20approv ed\%204\%2006\%202013\%20(2).pdf?ver=2013-06-27-221225-117

Howard, M. O. (2009). Beyond infrastructural issues: Informal barriers to social work research. Social Work Research, 33(3), 131-135. doi: https://doi.org/10.1093/swr/33.3.131

Jenson, J. M. (2008). Enhancing research capacity and knowledge development through social work doctoral education. Social Work Research, 32(1), 3-5. doi: https://doi.org/10.1093/swr/32.1.3

Jessiman, W. C. (2013). 'To be honest, I haven’t even thought about it'-recruitment in small-scale, qualitative research in primary care. Nurse Researcher, 21(2), 18-23. doi: https://doi.org/10.7748/nr2013.11.21.2.18.e226

Kurzman, P. A. (2015). The evolution of doctoral social work education. Journal of Teaching in Social Work, 35(1-2), 1-13. doi: https://doi.org/10.1080/08841233.2015.1007832

Kyriakakis, S., Waller, B., Kagotho, N., \& Edmond, T. (2014). Conducting safe research with at-risk populations: Design strategies from a study with unauthorized immigrant women experiencing intimate abuse. Qualitative Social Work, 14, 259-274. doi: https://doi.org/10.1177/1473325014538995

Lepp, L., Remmik, M., Karm, M., \& Leijen, Ä. (2013). Supervisors’ conceptions of doctoral studies. Trames: Journal of the Humanities and Social Sciences, 17(4), 401415. doi: https://doi.org/10.3176/tr.2013.4.06

Liechty, J. M., Liao, M., \& Schull, C. P. (2009). Facilitating dissertation completion and success among doctoral students in social work. Journal of Social Work Education, 45, 481-497. doi: https://doi.org/10.5175/JSWE.2009.200800091

Maynard, B. R., Vaughn, M. G., \& Sarteschi, C. M. (2012). The empirical status of social work dissertation research: Characteristics, trends and implications for the field. British Journal of Social Work, 44, 267-289. doi: https://doi.org/10.1093/bjsw/bcs123

Maynard, B. R., Vaughn, M. G., Sarteschi, C. M., \& Berglund, A. H. (2014). Social work dissertation research: Contributing to scholarly discourse or the file drawer? British Journal of Social Work, 44(4), 1045-1062.

Mirick, R. G. (2016). Challenges in recruiting parents to participate in child welfare research: Implications for study design and research practice. Child \& Family Social Work, 21(4), 484-491. doi: https://doi.org/10.1111/cfs.12165

Moore, S. E., \& Collins, W. L. (2002). African-American and clinical trials research: Recommendations for client engagement. Advances in Social Work, 3(1), 46-59.

Narui, M., Truong, K., \& McMickens, T. (2015). Independent study: How three doctoral students tackled issues recruiting participants and collecting data with historically underrepresented populations. Journal of Critical Thought and Praxis, 4(1), 1-34. 
National Association of Social Workers. (2008). Code of ethics. Retrieved from http://www.socialworkers.org/pubs/Code/code.asp

Ortega, D., \& Busch-Armendariz, N. (2014). Elite knowledge or the reproduction of the knowledge of privilege: Social work doctoral education. Affilia, 29, 5-7. doi: https://doi.org/10.1177/0886109913517162

Pettus-Davis, C., Grady, M. D., Cuddeback, G. S., \& Scheyett, A. (2011). A practitioner's guide to sampling in the age of evidence-based practice: Translation of research into practice. Clinical Social Work Journal, 39(4), 379-389. doi: https://doi.org/10.1007/s10615-011-0345-2

Rothwell, D., Lach, L., Blumenthal, A., \& Akesson, B. (2015). Patterns and trends of Canadian social work doctoral dissertations. Journal of Teaching in Social Work, 35(1-2), 46-64. doi: https://doi.org/10.1080/08841233.2014.977988

Rubin, A., \& Babbie, E. (2013). Research methods for social work. Boston: Cengage Learning.

Society of Social Work and Research. (2016). Annual conference clusters and topics. Retrieved from http://secure.sswr.org/

Thompson, S., \& Phillips, D. (2007). Reaching and engaging hard-to-reach populations with a high proportion of non-associative members. Qualitative Health Research, 17(9), 1292-1303. doi: https://doi.org/10.1177/1049732307307748

Thyer, B. (2014). The handbook of social work research methods. Thousand Oaks, CA: Sage.

Author note: Address correspondence to: Rebecca G. Mirick, PhD, School of Social Work, Salem State University, 352 Lafayette St., Salem, MA 01970.

rmirick@salemstate.edu 